\title{
HOJARASCA: UNA EXPERIENCIA PEDAGÓGICA Y DE CREACIÓN ARTÍSTICA ALREDEDOR DEL FEMINICIDIO
}

\author{
HOJARASCA: A PEDAGOGICAL EXPERIENCE AND OF \\ ARTISTIC CREATION AROUND FEMICIDE
}

\author{
HOJARASCA: UMA EXPERIÊNCIA PEDAGÓGICA E DE CRIAÇÃO \\ ARTÍSTICA EM TORNO DO FEMINICÍDIO
}

\author{
Alexandra Castañeda Obando ${ }^{1}$ \\ Francia Elena Mamian Ruiz ${ }^{2}$
}

\section{Resumen}

Este artículo de reflexión aborda una experiencia de creación artística llamada Hojarasca, la cual tiene como eje de investigación el feminicidio en Colombia, sus causas, sus formas y sus tipologías. Con ello, busca generar una reflexión que lleve a los participantes a cuestionar su papel respecto a un hecho como este. Los invita a encarnar a las víctimas, a ponerse en su lugar, a través de un cuestionario sobre su configuración familiar y de género, además de sensaciones con algunos objetos. La idea es trascender la mirada del espectador pasivo, invitarlo a ser parte de la obra y, con ello, generar una experiencia pedagógica significativa, ya que el criterio personal cambia cuando se asume el rol del violentado y se reconoce el entorno que este habita. Hojarasca tiene un enfoque metodológico basado en la indagación corporal personal, en la búsqueda del movimiento auténtico y expresivo, desde el lenguaje de la danza contemporánea. Apela al uso de los objetos y su valor semiótico, como ejes estructuradores de las memorias personales y colectivas. Al finalizar la acción, la colectiva acompaña sus sesiones con foros, donde intérpretes y espectadores exponen ideas, impresiones y reflexiones sobre la propia experiencia. El anhelo es avanzar hacia unas políticas públicas que prevengan el feminicidio y proporcionen mecanismos para contrarrestar una normativa violenta.

Pallabras clave: danza; performance; mujeres; cuestiones de género; educación cultural; diferencias de género

The reflection article deals with an artistic creation experience called Hojarasca, whose research axis is femicide in Colombia, its causes, its forms, and its typologies. This work seeks to generate a reflection that leads participants to question their role regarding an event like this. The spectator is invited to embody the victims, to be in their place, by means of a questionnaire about his family and gender configuration, as well as sensations with some objects. The goal is to go beyond the passive viewer's gaze, to invite them to be part of the performance, and, with this, to generate a significant pedagogical experience, since the personal criterion changes when the role of the victim is assumed and the environment that is inhabited is recognized. Hojarasca has a methodological approach based on a personal body research, in the search for an authentic and expressive movement from the language of contemporary dance. It draws on the use of objects and their semiotic value

1 Maestra en Artes Escénicas con énfasis en Danza Contemporánea de la Universidad Distrital. Historiadora de la Universidad del Valle. Docente de la Fundación Universitaria Católica Lumen Gentium. alexandracastanedaobando@gmail.com

2 Maestra en Artes Escénicas con énfasis en Danza Contemporánea de la Universidad Distrital. Especialista en Gestión Cultural con énfasis en Planeación y Políticas Culturales de la Universidad Nacional de Colombia. Docente de la Universidad del Valle. franciaelena. mamian@gmail.com 
as structuring axes of personal and collective memories. At the end of the action, the collective accompanies its sessions with forums. There, performers and spectators expose their ideas, impressions, and reflections about their experience. The idea is to move towards public policies that prevent femicide and provide mechanisms to counteract violent regulations.

Keywords: dance; performance; females; gender issues; cultural education; gender differences

\section{Resumo}

Este artigo de reflexão trata de uma experiência de criação artística chamada Hojarasca, cujo eixo de pesquisa é o feminicídio na Colômbia, suas causas, suas formas e suas tipologias, buscando gerar uma reflexão que leve os participantes a questionar seu papel em um evento como este. 0 espectador é convidado a encarnar as vítimas, expondo-se a responder a um questionário sobre sua configuração familiar e de gênero, que o leva a discernir, ao longo de suas respostas e através de sensações com alguns objetos, como poderíamos estar todos no lugar da vítima, transcendendo o olhar passivo do espectador e convidando-o a fazer parte da performance gerando, assim, uma experiência pedagógica significativa, pois o critério pessoal muda quando o papel da vítima é assumido e o ambiente habitado é reconhecido. Hojarasca tem uma abordagem metodológica baseada na pesquisa corporal pessoal, na busca do movimento autêntico e expressivo da linguagem da dança contemporânea, apela ao uso dos objetos em seu valor semiótico e como eixos estruturantes das memórias pessoais e coletivas. No final da ação, o coletivo acompanha suas sessões com fóruns, onde artistas e espectadores expõem ideias, impressões e reflexões diante de sua própria experiência; com o desejo de avançar para políticas públicas que previnam o feminicídio e forneçam mecanismos para combater as regulamentações violentas.

Palavras-chave: dança; performance; mulheres; questões de gênero; educação cultural; diferenças de gênero

Fecha de recepción: 22 de enero de 2019

Fecha de evaluación: 12 de febrero de 2019

Para citar este artículo:

Castañeda Obando, A., Mamian Ruiz, F. (2019). Hojarasca: una experiencia pedagógica y de creación artística alrededor del feminicidio. Lúdica Pedagógica, 29, 35-46. https://doi.org/10.17227/ludica.num29-11086 


\section{EL FEMINICIDIO COMO TEMA DE INVESTIGACIÓN}

La elección de este tema para la pieza Hojarasca tuvo que ver con la orientación que adquirió nuestro trabajo artístico en el marco de la colectiva3; veníamos centrándonos en la reflexión social a la luz de la perspectiva de género, luego de investigar sobre la cirugía estética y la diversidad sexual. El feminicidio fue una consecuencia lógica de la indagación por las formas de violencia contra las mujeres, y requiere tratamiento urgente dentro de la agenda social y política latinoamericana.

El feminicidio parte de las investigaciones de las aglosajonas Diane Russell y Jane Caputi (citadas en Segato, 2006), quienes, desde mediados de la década de los setenta del siglo pasado, impulsaron el término, aseverando que se trata de crímenes que se cometen contra las mujeres, más allá de cualquier factor, por el hecho mismo de ser mujeres. Según ellas:

El feminicidio representa el extremo de un continuum de terror antifemenino e incluye una amplia variedad de abusos verbales y físicos, tales como violación, tortura, esclavitud sexual (particularmente por prostitución), abuso sexual infantil incestuoso o extrafamiliar, golpizas físicas y emocionales, acoso sexual (por teléfono, en las calles, en la oficina y en el aula), mutilación genital (clitoridectomías, escisión, infibulaciones), operaciones ginecológicas desnecesarias (histerectomías gratuitas), heterosexualidad forzada, esterilización forzada, maternidad forzada (por la criminalización de la contracepción y del aborto), psicocirugía, negación de comida para mujeres en algunas culturas, cirugía plástica y otras mutilaciones en nombre del embellecimiento. Siempre que estas formas de terrorismo resultan en muerte, ellas se transforman en feminicidios (p. 3).

Según Boira, Marcuello-Servós, Otero, Sanz y Vives-Cases (2015), dicha definición representó un cambio de visión, así como un giro político y metodológico. Siguiendo a estos autores, el término se

3 Nuestro trabajo de investigación y creación hace parte de la colectiva Corpoaire Danza \& Género. Más allá del virtuosismo técnico y del arte por el arte mismo en la danza contemporánea, propone la creación de obras en varios formatos y diversos escenarios que denuncian problemáticas sociales, desde la valoración de la investigación personal. amplió gracias a los aportes de Campbell y Runyan (1998), quienes incluyen muertes que no son exclusivamente delitos, por cuanto no pueden ser adjudicadas a alguien. Allí, se encuentran aquellas causadas por acciones u omisiones, donde figuran la falta de sanidad y la desnutrición por razones de género, la trata de mujeres para el tráfico de drogas y la prostitución, el aborto en condiciones inseguras y el infanticidio, entre otros.

Esta conceptualización permite que el fenómeno tenga una dimensión más compleja, pues supone que el feminicidio no se limita a los actores que participan en el hecho delictivo, sino que involucra las prácticas socioculturales del conglomerado social, y esto amplía el horizonte de investigación e intervención.

Para el mundo hispanoparlante, la investigadora mexicana Marcela Lagarde (2008) perfila el concepto de feminicidio como la versión en castellano del término femicide. En Latinoamérica, el tema se volvió crucial a partir del asesinato masivo de mujeres en Ciudad Juárez, México, que en el periodo comprendido entre 1993 al 2001 ya reportaba cerca de 200 mujeres asesinadas de manera sistemática y bajo una impunidad imperante (Monárres Fragoso 2002) y que según datos de la fiscalía del Estado de Chihuahua para el año 2018, luego de 25 años, se llega a la cifra de 1,779 mujeres asesinadas (El Heraldo, 2018), lo anterior, ha concitado a los movimientos de mujeres a la producción académica, artística y al agenciamiento político.

Para nuestra investigación, también consideramos la clasificación que realizó Luz María Velázquez Reyes (2009) en su libro El cuerpo como campo de batalla. Según esta, la violencia se genera entre iguales (cuando es visible la intimidación, el acoso, el maltrato físico y psicológico, el hostigamiento, la victimización entre iguales, colocar a la víctima en una continua tensión y abuso sistemático [figura aquí la violencia doméstica]) o entre desiguales (en los casos de abuso de poder o de autoridad: el acoso laboral y sexual; la discriminación étnica, de género o religiosa; la humillación; gritos y maltrato físico o psicológico). En Colombia, en la mayoría de los casos de feminicidio, se presentan este tipo de agresiones entre desiguales. Autoridades de diferentes jerarquías, grupos armados y delincuencia común suelen 
ser los autores involucrados. También hay que considerar que la violencia psicológica crea entornos asimétricos de relación, que son difíciles de desentrañar. Allí, el arte cumple un papel trascendental en los procesos de conciliación y transformación.

Estas discusiones, merced al movimiento de mujeres, han llegado al terreno judicial en la mayor parte de los países latinoamericanos; sin embargo, el problema ha avanzado con contratiempos, básicamente por razones culturales. En lo que coinciden la mayoría de las investigadoras es en la naturalización social que existe frente a las formas de violencia contra las mujeres, como diría Rita Laura Segato (2006): “En un medio dominado por la institución patriarcal, se atribuye menos valor a la vida de las mujeres y hay una propensión mayor a justificar los crímenes que padecen" (p. 3).

Los contextos latinoamericanos han estado signados por la guerra, y este hecho recrudece las formas de violencia contra la mujer y el feminicidio, como su máxima expresión. En ese orden, el feminicidio, en el contexto colombiano, se ha utilizado como forma de persecución y aniquilación política.

En el marco del conflicto armado, se han cometido todo tipo de delitos sexuales, pero los de género han sido difíciles de desentrañar, por la naturalización hacia la violencia contra la mujer y contra la población LGTBI. Esto da pie a la revictimización en las instituciones del Estado, es decir, a la culpabilización de la víctima por lo sucedido. Esta queda marcada y segregada, lo que, a la postre, no le permite superar el hecho traumático.

Según el informe ;Basta ya! Colombia: memorias de guerra y dignidad (2014), del Centro de Memoria Histórica, muchas veces los profesionales de la rama judicial reproducen los estereotipos y, con ello, perpetúan la cadena violenta.

En ese contexto, se registra la aplicación de procedimientos legales inadecuados para investigar los hechos y para atender a las víctimas, procedimientos que terminan por desestabilizarlas emocionalmente o por violentarlas de nuevo. En sus testimonios, las víctimas denotan reacciones de funcionarios o funcionarias que sutilmente las acusaron de haber inducido estos crímenes o que, inspirados en representaciones estereotipadas de la violencia sexual, no creyeron la veracidad de sus testimonios, es decir, no aplicaron el principio de buena fe: "El otro día llegó una mujer a decirme que había sido violada. Pero el relato era poco creíble porque era fea y vieja" (p. 77).

Como respuesta a lo anterior, se han dado cita una serie de manifestaciones artísticas en el continente, sobre todo en México, pero también en otros países latinoamericanos. Muchas organizaciones, colectivos, mujeres artistas y activistas apelan al performance como una forma contundente de denuncia política.

$\mathrm{Al}$ respecto, desde Chiapas, México, se creó, el 14 de abril de 2012, una plataforma llamada Arte-acción, con presencia digital. Nació a partir del feminicidio de una mujer indígena llamada Itzel Janet Méndez Pérez. Sus integrantes realizan intervenciones en espacios públicos, que congregan a artistas e intelectuales. Estas performistas trabajan lo decolonial, lo pedagógico y lo erótico. Este último, lo releen en oposición a lo sexual, como un campo de posibilidades que abren los sentidos y conectan con la propia vitalidad.

De igual forma, cabe resaltar el trabajo artístico de la performer guatemalteca Regina José Galindo, quien ha adoptado el apelativo "perra" como una forma de protesta, y marca su cuerpo con aquel. Su inspiración son los múltiples feminicidios cometidos durante la guerra civil en Guatemala, donde las mujeres, antes de su ejecución, eran torturadas y marcadas. Sin duda, su acción le ha traído choques con el establecimiento, pero ha permitido visibilizar la enorme violencia que existe en dicho país contra las mujeres.

La performer resalta cómo el cuerpo mutilado de estas mujeres se reduce a restos, en una forma de deshumanización de la muerte propia de la Modernidad. Esta obra ha sido sustrato creativo para Hojarasca, en la medida en que una de sus escenas deja ver mujeres en una fosa común, cubiertas bajo un manto de hojas secas.

Hojarasca hace parte de esas búsquedas por reflejar, en el arte, una problemática social. Pese a lo lejana que pueda parecer esta realidad para algunas mujeres, basta dar una mirada por la genealogía de cada una, para reparar en que somos herederas de esas violencias propias de un país que no parece haber vivido periodos prolongados de paz, pero sí 
un estado de guerra permanente. En consecuencia, nuestra indagación interpretativa halló una gran fuente creativa en las propias estructuras familiares que engendran las formas comportamentales heteropatriarcales facilitadoras de violencias hacia lo femenino.

\section{LA AUTENTICIDAD CORPORAL Y LA VIVENCIA PERSONAL COMO MATERIA PRIMA DE CREACIÓN}

Reconocer la autenticidad corporal y, en esa ruta, el valor de la vivencia personal se convierte no solo en una postura personal, sino además en un enfoque pedagógico y metodológico, desde donde se percibe el proceso de creación y la práctica artística.

La experiencia artística permite que el individuo se reinvente y no se limite a seguir ciertos cánones estilísticos. En lo que respecta a la danza, parte de reinventarse es asumir que cada persona tiene su propia manera de bailar y de crear a través de su cuerpo y de sus circunstancias, porque cada cuerpo es particular, y de allí emerge su riqueza creativa. En ese orden de ideas, el individuo realiza una búsqueda propia, donde reconoce su propio cuerpo en su unicidad, y no como molde por ser homogeneizado. En ese sentido, es importante la identificación de cada sujeto consigo mismo para explotar sus posibilidades expresivas y creativas. Es la vía de la maestra y creadora de la expresión corporal, Patricia Stokoe, quien marca, en Latinoamérica, una ruptura con las formas de concebir la danza y el movimiento, proponiendo una búsqueda más personal del movimiento, que conduce a procesos creativos más honestos y prolíficos.

[...] su interés se centra en la creación de una técnica que habilite y prepare al individuo para la danza por fuera de los modelos tradicionales que implicaban un uso del cuerpo ligado casi exclusivamente al rigor, muchas veces al dolor y a la copia de modelos (casi imposibles de igualar) como modalidad exclusiva de formación (Yutzis, 2013, p. 4).

Ser bailarinas-creadoras y maestras nos lleva a indagar en una identidad cultural, corporal y social propia, más allá de acceder a una información similar. En cuanto a las técnicas de danza, y como maestras en el ámbito de la escuela de danza, ha sido impor- tante encontrar esa particularidad interpretativa de cada una, como lo plantea la maestra cubana María del Carmen Mena (2009). Se trata de asumir nuestro cuerpo como punto de partida, en términos identitarios, e intermediario de conocimiento desde la práctica pedagógica.

En ese orden de ideas, somos una acumulación sociohistórica; funcionamos como una colectiva de producción artística que piensa el arte en relación con el contexto histórico, entendiendo que somos parte del mismo. En nuestro oficio como bailarinas de danza contemporánea, tenemos una fuerte influencia del realismo desde la expresión del cuerpo físico -legado que dejaron Pina Bausch y maestros como Eugenio Barba, Peter Brook y Jerzy Grotowski- o, en palabras de Antonin Artaud (citado por Mangieri, 2010), "del actor como atleta de las pasiones y las emociones". Vivir el límite de lo real e imaginario nos lleva a una experiencia del cuerpo a través de la vivencia y nos cuestiona sobre la otredad de los cuerpos en contextos diferentes, aún más cuando pensamos en abordar ciertas temáticas sociales de forma creativa. Nos conduce también a la interculturalidad, como lo anota Mangieri (2010):

Es a partir de este momento que se puede hablar de interculturalidad como tal. Lo intercultural supone previamente el reconocimiento del otro, la otredad como valor, como objeto de valor, incluso como significante enigmático y seductor del cual todavía no conocemos sus efectos y sentidos pero que nos atrapa en la red de su producción significante (p. 2).

Estos paradigmas conceptuales también nos llevan a un quehacer pedagógico que apunta hacia una comprensión más compleja del cuerpo, como escenario mediado por oposiciones (físicas y emotivas), un cuerpo presente, vivo.

En el caso particular de nuestra experiencia como colectiva artística, adoptamos este enfoque de trabajo; si bien hay una dirección coreográfica, los intérpretes alimentan la creación desde sus vivencias personales. De ese modo, cuando abordamos el tema de la creación, nuestras historias de vida se mimetizan con el acto creativo. Esta es la premisa en la búsqueda de autenticidad. El proceso de composición empieza desde la autobiografía de los participantes, lo que logra un compromiso afectivo con la 
propuesta; la escritura autobiográfica se consigna en diarios de campo, pero es en el cuerpo donde se expresa con mayor impacto. La escritura autobiográfica no tiene mucho interés como documento válido para la academia tradicional, pero implica un ejercicio de empoderamiento individual y colectivo, sobre todo en el marco de un trabajo orientado por la perspectiva de género, como diría Heilbraun (citado por Cao, 2014):

No importa el nivel de compromiso que la autobiógrafa asume en su esfuerzo por autorrepresentarse: el mismo acto de asumir el poder de autoexponerse públicamente cuestiona las ideas y normas del orden fálico y representa una forma de desorden, un tipo de herejía que pone al descubierto un deseo femenino transgresivo (Heilbrun, 1988).

En ese sentido, hacer el ejercicio de autobiografía lleva a un contacto honesto y profundo con el yo, revalorando las situaciones del pasado y reflexionado frente a ellas. La investigadora Marian López Fernández-Cao (2014) proporciona unas características de la escritura autobiográfica femenina que aportan al empoderamiento individual. En la medida en que se socializan en el empoderamiento colectivo, según ella, la escritura autobiográfica lleva a la autoafirmación, más que a la exaltación del yo y a una mirada narcisista. En dicha escritura, la cotidianidad desempeña un rol importante, así como los lazos familiares y, sobre todo, las experiencias personales en relación con los otros. Más que separaciones con los demás actores, se encuentran conexiones; las narraciones no son cronológicas, sino fragmentarias y discontinuas.

Aparece un yo descentralizado en el cual los seres queridos aparecen como elementos vitales en el proceso de concienciación. [...] El acto de recordar intrínseco en la vuelta al pasado utiliza la selección de unos recuerdos y no de otros, y la citada elección coincide con la referencia a la parcelación del mundo con el cual la mujer entra en contacto. La falta de una meta prefigurada se impone tanto en la estructura como en el plano sintagmático y en el estilo de configuración. De ahí que la estructura no sea lineal, sino repetitiva, acumulativa, cíclica, disyuntiva, que señala una fragmentación del relato. [...] La interrupción, la supresión, la repetición, la incorporación de la oralidad, la presencia de otros/ as narradores/as, la función fática, aparecen como elementos sintácticos a los cuales recurren las autoras a la hora de explicar sus propias vidas (Cao, 2014, pp. 34-35).

Este ejercicio de reflexión autobiográfica es una fuente inagotable para la creación artística; implica, de una manera más concreta, a las intérpretes-creadoras y juega con los recuerdos, los objetos y su simbolismo.

También desempeñan un rol preponderante en el proceso de creación los cuestionarios de preguntas acerca de las temáticas que la colectiva quiere tratar. Así, se componen las escenas y, posteriormente, la práctica dancística, a través de técnicas somáticas y de otras inspiradas en Laban y en Bartenieff.

Todo parte de búsquedas autobiográficas, preguntas, respuestas, reflexiones, comunicación intrapersonal y colectiva; luego, se proyecta en la acción escénica; cuando termina esta acción, se confrontan la vivencia y el conocimiento adquirido desde la experiencia, buscando una construcción desde las emociones, percepciones y sensaciones.

De la mano con la experiencia artística, nuestro interés es que en el campo de la investigación pedagógica se explore la vivencia. En esa medida, el conocimiento es significativo y, aún más, es construcción senti-pensante. Como lo argumenta Facundo Ferreirós (2016), el aprendizaje se genera desde la experiencia vivida.

Dentro de nuestra práctica, reconocemos el contexto sociopolítico de nuestro país, Colombia, que carga rasgos de violencia de una generación a otra, violencia enraizada durante muchos años, por el conflicto interno armado, en el marco de un país con profundas desigualdades sociales, un Estado precario y unas estructuras políticas que han facilitado la inequidad social y la corrupción. Dicha violencia ha alimentado las estructuras patriarcales en las que los hogares colombianos se han erigido, y el cuerpo ha sido el escenario por excelencia de una violencia permitida.

Siguiendo a Ferreirós (2016), cuando pensamos en el cuerpo como territorio, lo descolonializamos; posibilitamos la construcción de nuevas realidades e imaginarios a través de una democratización de las prácticas artísticas corporales en los procesos educativos. Así, proponemos que la práctica escénica del cuerpo y la danza no se reduzca al acto escénico en 
un escenario tradicional como el teatro, sino que se proyecte y perviva en la experiencia del espectador, en su inconsciente y en sus memorias. Para tal fin, ha sido preciso recurrir al performance como vehículo.

Al respecto, fue de vital importancia para nosotras plantear un acto creativo como hecho de paz, recalcando que la violencia no solo habita en los territorios en conflicto, sino que está adscrita a nosotras, a nuestros recuerdos, a nuestra cotidianidad en los diferentes espacios de interacción social. En ese sentido, hemos sido sobrevivientes de la historia violenta que se engendra y sigue reproduciéndose, y de ello emana una responsabilidad. En consecuencia, nuestra forma de contribuir a la paz es desde una pedagogía del reconocimiento, donde exponemos nuestros cuerpos, constructos de experiencias; nos disponemos a la experiencia estética y buscamos la sanación colectiva a través del acto ritual del arte escénico.

\section{HOJARASCA: UNA EXPERIENCIA ARTÍSTICA Y PEDAGÓGICA}

Hojarasca es una experiencia artística y pedagógica, con la cual emprendimos un proceso de creación y aprendimos en el camino. Nació de nuestras búsquedas de nuevas formas de creación artística y de elementos que sensibilicen al espectador frente a una problemática concreta. En este proceso, vinculamos conceptos propios del discurso académico y político para, a través del arte, traducirlos a lenguajes estéticos. En el caso particular de esta pieza, nos preguntamos sobre el feminicidio: sus causas, su tratamiento judicial, las condiciones que lo favorecen y sus huellas en los cuerpos de las mujeres.

Durante el proceso de creación, realizamos laboratorios de exploración en los cuales tomamos varios insumos. Por un lado, casos específicos de mujeres que lo padecieron y que murieron en diferentes circunstancias, según lo dictaban las tipologías de feminicidio que logramos esclarecer. Dentro de estas, encontramos mujeres asesinadas por sus compañeros o excompañeros sentimentales; por personas del entorno familiar; mujeres que fueron agredidas por hombres ajenos a sus contextos inmediatos; mujeres asesinadas por el estigma del oficio al cual estaban asociadas; por su condición no binaria, diversa o transexual, entre otros. Por el otro, la investigación autobiográfica, que cumplió un papel trascendente. El ejercicio de recordar los casos de violencia de género dentro de nuestros linajes familiares e historias personales fue una fuente de creación para personajes y escenas.

Posteriormente, se pasó por un proceso de exploración de movimiento a partir de objetos que estaban vinculados con los casos seleccionados para la interpretación; dichos objetos se circunscriben a la intimidad de cada mujer. La improvisación arrojó secuencias de movimiento que partían de corporalidades propias y variadas cualidades de movimiento que se conectaban con los intereses interpretativos de las escenas. La derivación de secuencias de movimiento, desde la exploración del rango de movilidad de las articulaciones (caderas, hombros, cabeza, etc.), contribuyó a crear secuencias únicas que vinculan, con especial ahínco, una zona del cuerpo con una situación determinada, un recuerdo. En ese sentido, el movimiento emergió de una memoria emotiva de las violencias sufridas, y el cuerpo se convirtió en un escenario donde los recuerdos se alojan. Como diría la investigadora Raquel Guido (2014):

El cuerpo contiene en sí el registro de toda la historia del sujeto desde aquellas tempranas etapas fetales. Esta historia encarnada en sensaciones e imágenes que se alojan en el inconsciente se despliega en el movimiento poniendo en juego una dramática inconsciente, imaginaria, poética, que no responde a la gestual codificada como lenguaje de la vida cotidiana, ni a su orden (p. 184).

Durante la investigación hubo descubrimientos, confrontación y, al final, aceptación del nivel de riesgo por el que atravesamos. Concebimos la obra como una oportunidad para transmutar los dolores.

Hojarasca es una experiencia que ha pasado por diferentes formatos, entre los que figuran la obra danzada, el foro y, posteriormente, la acción performance. Para esta última, los objetos y su relación con los sentidos cobran una relevancia máxima en la exploración de la memoria y la reflexión emergente frente a las violencias que los participantes han vivido y que constituyen la antesala a un hecho tan fatal como el feminicidio.

Los objetos están en contacto con nuestros sentidos y están llenos de memoria. Recordar implica recorrer nuevamente los caminos que alguna vez transitamos; 
la memoria está plagada de sonidos, olores, texturas, imágenes y pequeños detalles, donde los objetos desempeñan un papel relevante. En el performance, su presencia habla por sí misma.

Con el ánimo de captar la atención del público y ponerlo en sintonía con el feminicidio, introducimos al espectador en la violencia, que, más allá de la condición étnica, cultural y socioeconómica, pervive en la forma de relacionarnos.

Para darle profundidad al trabajo, utilizamos la sensopercepción, técnica creada por la maestra Patricia Stokoe en el contexto de la posguerra, luego del sometimiento del cuerpo a la más cruda limitación de los campos de concentración. Surge de la mano de la eutonía de Gerda Alexander y de los aportes de la autoconciencia del movimiento de Moshe Feldenkrais. Su propósito es generar consciencia corporal a través del registro de estímulos, sensaciones y percepciones que afectan los sentidos. Este proceso con los estímulos externos conecta al participante con memorias emotivas y lo conduce a una puerta de discernimiento del inconsciente. En esa vía, Hojarasca se propuso generar una atmósfera de sentidos donde los participantes podían conectar emociones, sensaciones, recuerdos y sentimientos, para luego traducirlos en una reflexión consciente, en una toma de decisión y empoderamiento.

La acción performance de Hojarasca empieza con un cuestionario sencillo, con algunas preguntas directas y otras sugerentes, que se van ampliando según los laboratorios lo van demandando. Los participantes responden a medida que van avanzando (o quedándose en el lugar), con los ojos vendados, por un camino que les lleva a medir su nivel de riesgo y, con ello, su cercanía a ser víctimas de feminicidio.

El cuestionario lleva al participante hacia su pasado familiar, haciéndole recordar actitudes, palabras y comportamientos que influyen en su configuración de género y de familia. La acción está ambientada por una voz en off que el espectador escucha con los ojos cerrados mientras recorre una ruta marcada por texturas, sonidos y olores hasta llegar a los casos judiciales. Estos se clasifican de menor a mayor impacto y conducen a los participantes hacia una valoración de su nivel de riesgo y a una identificación con las víctimas. Cuando finalizan los casos, se revela que dichos crímenes no discriminan edades, roles sociales ni estratos; que suceden de manera común en el género femenino y en géneros que se identifican con el mismo. Los elementos, al inicio, destacan un valor sutil de cada caso y, luego, sugieren la forma agresiva de lo sucedido. El espectador es testigo y se relaciona con los objetos que se utilizaron con su propia experiencia o contexto.

Además de la connotación cotidiana, los objetos tienen su propia voz: son las voces de las víctimas, los rastros del delito, la casualidad que nos une a todos con aquellas y la escena del crimen; las imposiciones sociales establecidas, que nos vulneran ante un Estado permisivo que absuelve a los culpables mientras abre la puerta a la impunidad.

Después, los participantes se confrontan con dos mujeres que representan la bipolaridad de la vida y la muerte y que narran, corporalmente, la afectación de la violencia cultural y, luego, la muerte en la fragmentación del cuerpo que cae. No obstante, Hojarasca propone, además, la reconciliación con la vida mediante el abrazo de los cuerpos en una danza hacia la sororidad, como alternativa para superar la violencia, y un gesto de acogernos unos a otros a través del contacto con los participantes-espectadores.

Hojarasca busca que más allá de casos muy puntuales, inscritos en contextos particulares, se comprenda que la sociedad, en su conjunto, está involucrada. Subraya cómo estas violencias no pertenecen al universo de lo otro, lo ajeno, crímenes perpetrados por extraños, locos, individuos anómalos, sino que todos, por lejanos que queramos percibimos, pertenecemos a una matriz heteropatriarcal profundamente feminicida. Siguiendo ese orden de la argumentación, la sociedad, merced a sus diferentes dispositivos, recurre a señalar a las víctimas y a los agresores, $\mathrm{y}$, con ello, a diferenciarlos de los otros. Esto termina por ocultar la responsabilidad social de las instituciones estatales y del orden cultural. Como lo anota el sociólogo Rigoberto Reyes Sánchez (2012), las prácticas de extrañamiento y ocultamiento son prácticas feminicidas.

Primero el extrañamiento sobre la víctima: su asesinato es justificado socialmente al construirla como una extraña, un sujeto extraterritorial o discordante en la comunidad (la migrante, la prostituta, 
la marginada económica, la que no cumple con ciertos estereotipos de género). Al caracterizar a la víctima como un 'ajeno', la sociedad busca salvarse; sin embargo, cuando la brutalidad interrumpe tan decididamente la cotidianeidad, evidenciando que la violentada no es solo 'la otra', sino, potencialmente, cualquiera, se activa la siguiente estrategia de distanciamiento: la configuración social del chivo emisario (Girard), encarnación de la maldad, vicario del horror. Tras su cacería, es sometido por el sistema penal: su cuerpo encerrado expía las culpas sociales. La creación del chivo expiatorio cumple una función tranquilizadora, pues al responsabilizar a "el egipcio", al gringo, al narco o simplemente a "el loco", la sociedad queda libre de culpa: el agente anómalo solo debe ser extirpado del cuerpo sano. Sin embargo, ni las detenciones ni los alejamientos detienen los feminicidios (p. 2).

En la vía de Reyes (2012), buscamos, a través de Hojarasca, que el espectador se reconozca en esta realidad y comprenda cómo participamos de lo que él llama "el pensamiento sacrificial". Según este, una sociedad acepta el sacrificio de lo que le resulta incómodo al establecimiento:

El sacrificio de la víctima propiciatoria -la mujer pobre, la activista incomoda, la migrante- es un mecanismo de salvación, se acepta la muerte, la destrucción total de un miembro percibido como "inferior" (machismo por medio) de la sociedad, a cambio de mantenerse a salvo: la vida tranquila, como un beneficio que tiene como precio la sangre ajena (p. 3).

En suma, de toda la vivencia con Hojarasca, en sus diferentes formatos (como obra danzada, foro y performance), queda una gran conclusión: la certeza de que la obra artística, lejos de ser un producto, es una experiencia y, como tal, lleva consigo un aprendizaje. Luego de este proceso, no podemos afirmar ser las mismas personas; quienes trabajamos como intérpretes-creadoras o como participantes del foro o del performance nos llevamos una reflexión profunda respecto a la forma en que, por acción u omisión, el feminicidio nos ha afectado y alimentamos las diversas violencias de género. La experiencia artística, en esa medida, se convierte en una experiencia pedagógica, donde hay un antes y un después en el individuo, cuyos hallazgos alimentan posibles intervenciones en el contexto.

\section{LA EXPERIENCIA ARTÍSTICA COMO EXPERIENCIA PEDAGÓGICA}

Pensar el arte y la pedagogía como experiencia pasa por desacralizar la obra de arte - para el caso, la obra escénica- y concebirla como resultado de un proceso de investigación, donde la experiencia artística, personal y colectiva, adquiere un valor fundamental. Dicha experiencia deja reflexiones que aportan a la construcción de conocimiento, y esto da lugar a una construcción pedagógica, desde la valoración de la experiencia de quienes participan del hecho creativo. En ese sentido, podríamos deducir que una experiencia artística es una experiencia pedagógica.

La obra de arte ya no se percibe como el producto de un acto de genialidad de un individuo en un momento de inspiración determinado; en cambio, se comprende como un hecho social. Viviendo la experiencia artística de creación, va emergiendo la obra, no mediante una idea preconcebida, sino en construcción con los participantes, desde la conjunción de subjetividades.

$\mathrm{Al}$ introducirse en el acto creativo, cada sujeto se reinventa. La obra no es algo ajeno a sí mismo; en oposición, se integra con la vida misma, por cuanto la reflexión emerge del mismo quehacer artístico, del ejercicio pedagógico. En palabras de Zulai Macías Osorno (2009):

Veremos que el papel asignado al arte será el de fungir como el puente que traslada al ser escindido de lo externo hacia lo infinito para acceder al reencuentro con aquella lejanía de la obra y fundir al arte con la totalidad de la vida. [...] Ya no postula la intuición intelectual capaz de engendrar su objeto, sino como reflexión que produce su propia forma (p. 19).

Entonces, no se trata ya de un hecho de inspiración e intuición meramente intelectual, pero sí de una búsqueda personal en interacción con el entorno. La experiencia dentro de la obra produce reflexiones profundas que se traducen en conocimiento.

En ese orden de la argumentación, las experiencias artísticas como experiencias pedagógicas pueden tener un lugar extramuros; los espacios públicos son escenarios del ejercicio pedagógico, y las comunidades son participantes de los mismos. En la vía decolonial de Catherine Walsh (2007) y de la pedagogía 
de la liberación de Paulo Freire (1982), la pedagogía se ancla a las luchas populares donde se aprende y se desaprende, por ende, desborda los espacios escolares.

De igual forma, creemos que es el momento de no subestimar y marginar la importancia de la corporalidad en la formación de la conducta y la personalidad, pero sí de visualizar la exploración de temáticas como la violencia de género, la diversidad sexual y la discriminación racial a través de la práctica escénica, además de otros aspectos que muchas veces se evaden en los procesos artísticos y pedagógicos, en función de priorizar obras de poca sustancia artística y conceptual, diseñadas para el consumo masivo y promovidas por la industria cultural.

La prevención de la violencia de género, pese a los esfuerzos de los últimos años, aún representa un tabú en las instituciones educativas y en los hogares colombianos. Sigue pasando por alto su vínculo con el acoso escolar, el abuso de poder a diferentes niveles, el bullying y el suicidio infantil y juvenil. Avanzar en estos temas y buscar otras alternativas de abordaje pedagógico que superen el modelo tradicional representa un reto para maestros e instituciones y podría llevarnos hacia contextos menos violentos, donde el cuerpo no reproduzca conductas de abuso, sino que sea un territorio propio, auténtico.

\section{HALLAZGOS Y CONCLUSIONES}

Los hallazgos frente al performance fueron diferentes a lo esperado. El cuestionario enfatiza en las mujeres: somos mujeres, pensamos desde allí. Pensábamos que eran ellas las que avanzarían más en la concienciación de lo vulnerables que estaban en el contexto patriarcal, pero no fueron quienes lo reconocieron fácilmente. Esto nos permitió concluir que darse cuenta de qué tan cerca está la violencia de uno toma tiempo, tiempo para reflexionar. Así lo demostró una compañera que se sometió al cuestionario varias veces, cada vez llegando a respuestas diferentes, respuestas que ratificaron el riesgo en el que estaba.

Lo que encontramos en varias mujeres fue la negación: "Esto no me ha pasado a mí, yo no he sido sujeto de violencias". Quizá esta sea la reacción de la sociedad evasiva en la que vivimos; en la que preferimos cerrar los ojos y cubrir el susurro del inconsciente antes que mirar a la cara la violencia de la que hacemos parte. Ello tiene que ver con la internalización de la violencia, lo que supone la naturalización de la misma, como lo resalta la investigadora Graciela Freyermuth Enciso (2008):

Un tercer elemento que hace posible la perpetuación de la violencia es la "internalización", por parte de las personas afectadas o de las víctimas, de su condición de subordinación que les confiere una limitada capacidad para tomar decisiones en diversos ámbitos como la familia, la comunidad o las instituciones gubernamentales, o para exigir el cumplimiento de o de sus derechos permitiendo igualmente la perpetuación de la violencia estructural (p. 185).

En el desarrollo del cuestionario, también descubrimos que partir del principio de la configuración familiar y de género es un buen comienzo, pues es en esa intimidad donde todos - hombres, mujeres y géneros no binarios - podemos concienciarnos de la violencia transitada y del riesgo del sujeto femenino. Llamó la atención que el mayor avance se presentara en personas de la comunidad LGTBI. De esto, se deduce que su condición no binaria les hace muy vulnerables, y dicha vulnerabilidad es ostensible, pero nuestro conservadurismo social y jurídico es aún muy grueso para evidenciarlo, como dirían las performistas mexicanas Chávez y Difarnecio (2014):

En consecuencia, las transmujeres, intersex, transexuales y cualquier otro cuerpo disidente, pero con identificación femenina propia, pueden ser víctimas de feminicidio. En la literatura jurídica y académica, estos cuerpos no están incluidos. Inclusive, no aparecen en los medios de comunicación. En muchos casos, ni siquiera son reconocidos como homicidios porque socialmente estas personas transgreden las políticas normativas de lo que puede ser el sexo y el género de una persona (p. 34).

La experiencia también nos supone el reto de seguir afrontando una sociedad que siente pudor ante la palabra feminismo y que, en nombre de la calma social, procura seguir el molde de la mujer "buena", en lugar de transitar el incierto lugar de la honestidad consigo misma. Como resultado, ya no somos solo bailarinas, solo creadoras; somos parte de un 
proceso de pedagogía social: creamos para no morir, creamos para que valga la pena estar en el arte, creamos porque es nuestra única salida, porque es una misión de vida. Al crear aprendemos, y en el aprender enseñamos.

Todo el proceso de construcción de la obra Hojarasca, en sus diferentes formatos, nos llevó a una investigación desde nuestra propia subjetividad, en conexión con el contexto social. Esta nos permitió ratificar nuevamente que lo personal es político y lo político es personal; que las experiencias subjetivas construyen conocimiento. Además, en la medida en que encarnamos los personajes de la obra y nos exponemos en el acto escénico, generamos senti-pensamiento, es decir, pensamiento modelado desde lo corporal, y logramos que el gesto contara desde la honestidad de habernos sentido involucradas. Ello implicó rupturas internas y colectivas, para comprender mejor de qué se trata la sororidad y en qué momento estamos. Sin duda, este proceso de experimentación, exploración, investigación y creación nos prepara para encarar los procesos pedagógicos con más propiedad, entendiendo que la distancia entre el sujeto que estudia y lo estudiado que nos legó el positivismo no lleva a que la sociedad se sensibilice realmente. En cambio, reconocerme en el conflicto del otro teje de una manera más profunda y me dispone a la comprensión de una problemática. Un proceso pedagógico sin compromiso afectivo no logra ser efectivo; no consigue ser significativo ni transformador.

\section{REFERENCIAS}

Bidaseca, K. (2013). Feminicidio y políticas de la memoria. Exhalaciones sobre la abyección de la violencia contra las mujeres. En Hegemonía cultural y políticas de la diferencia. Buenos Aires: Clacso.

Boira, S., Marcuello-Servós, C., Otero, L., Sanz Barbero, B. y Vives-Cases, C. (2015). Femicidio y feminicidio: un análisis de las aportaciones en clave iberoamericana. Comunitania. Revista Internacional de Trabajo Social y Ciencias Sociales, 0(10), 27-46. https://doi. org/10.5944/comunitania.10.2

Cao, M. L. F. (2014). Aplicando metodologías feministas para analizar la creación: propuestas en educación artística desde la experiencia de las mujeres. Dossiers feministes, (19), 31-55.
Centro de Memoria Histórica (2013). ;Basta Ya! Colombia: Memorias de guerra y dignidad. Bogotá: Centro de Memoria Histórica.

Campbell, J., y Runyan, C. W. (1998). Femicide: Guest editors' introduction. Homicide Studies, 2(4), 347-352.

Chávez, B. y Difarnecio, D. (2014). Decolonizando acciones públicas contra el feminicidio con cuerpos disidentes: el performance y la plataforma arte acción en Chiapas México. Calle 14: Revista de investigación en el campo del arte, 9(14), 30-43.

Fragoso, J. M. (2002). Feminicidio sexual serial en Ciudad Juárez: 1993-2001. Debate feminista, 25, 279-305.

Ferreirós, F. (2016, 10 de abril). Hacia una pedagogía del cuerpo vivido: la corporalidad como territorio y como movimiento descolonizador. Cartografías Pedagógicas Latinoamericanas. http://descolonizarlapedagogia. blogspot.com.co/2016/04/hacia-unapedagogia-del-cuerpo-vivido.html

Freire, P. (1982). La educación como práctica de la libertad. Siglo XXI.

Freyermuth, G. y Argüello, H. (2010). La muerte prematura de mujeres en los altos de Chiapas. Un análisis desde la violencia. Revista Pueblos y Fronteras Digital, 6(10), 181-216.

Guido, R. (2014). De la percepción del propio cuerpo al despliegue poético de la danza. Ponencia presetada en el I Congreso Internacional de las Artes, Madrid, España. https://congresointernacionaldeartes.una.edu.ar/ files/actas/0114.pdf

Macías Osorno, Z. (2009). El poder silencioso de la experiencia en la danza contemporánea. Bilbao: ArtezBlai.

Lagarde, M. (2008). Antropología, feminismo y política: violencia feminicida y derechos humanos de las mujeres. En Retos teóricos y nuevas prácticas (pp. 209-240). Ankulegi.

Mangieri, R. (2010). Cuerpos en interacción: teatro, danza y multiculturalidad. Actual. Revista de la división de Cultura y Extensión, (71), 104-111.

Martínez Prado, H. (2018, 15 de febrero). En 25 años van 1,779 feminicidios en Ciudad Juárez. El Heraldo. https://heraldodemexico.com.mx/estados/ en-25-anos-van-1775-feminicidios-en-ciudad-juarez/

Reyes, R. (2012). Las muertas de Juárez: producir arte desde el trauma social. Intersticios de la política y la cultura. Intervenciones latinoamericanas, 1(2), 1-6. https://revistas.unc.edu.ar/index.php/intersticios/ article/view/5375 
Rodríguez, M. (2009). Cuerpo creativo: taller cubano para la enseñanza de la composición coreográfica. Buenos Aires: Balletin Dance.

Segato, R. (2006). Qué es un feminicidio. Notas para un debate emergente. Brasilia: Universidad de Brasilia.

Velázquez, R. (2009). El cuerpo como campo de batalla. México: Fondo Editorial Estado de México.
Walsh, C. (2007). Interculturalidad colonialidad y educación. Revista Educación y pedagogía, 19(48), 25-35.

Yutzis, D. (2013, 9-13 de septiembre). Sensopercepción, otras lógicas del cuerpo. [Ponencia]. x Congreso Argentino de Educación Física y Ciencias, La Plata, Argentina. http://www.memoria.fahce.unlp.edu.ar/trab_eventos/ ev.3089/ev.3089.pdf 